\title{
Botryosphaeria dothidea associated with grapevine decline disease in Iran
}

\author{
M. Arzanlou • S. Moshari • M. Bakhshi • S. Khodaie
}

Received: 23 January 2012 / Accepted: 30 October 2012 / Published online: 14 November 2012

(C) Australasian Plant Pathology Society Inc. 2012

\begin{abstract}
Since 2008, there have been several reports on the occurrence of decline symptoms on grapevines in vineyards of East and West Azerbaijan provinces in Northern Iran by local farmers as well as plant protection clinics. The disease symptoms appeared as stunted growth, shoot dieback and wedge-shaped wood necrosis in cross section through the wood. Isolations were made from the surface sterilized tissues using routine plant pathology techniques. Based on the sequence data of ITS-rDNA and morphological characteristics of the conidia, the isolates were identified as Botryosphaeria dothidea. Pathogenicity assay using an excised shoot method revealed the isolates being pathogenic on grapevine. This is the first report on the occurrence of Botryosphaeria dothidea on grapevine in Iran.
\end{abstract}

Keywords Vitis vinifera $\cdot$ Wedge-shaped canker · Trunk diseases $\cdot$ Excised shoot method

Iran's grapevine industry presently covers 286,000 ha with annual production of $3,000,000 \mathrm{t}$, playing a significant role in country economy (FAO 2009). Iran is also considered as one of the presumed centers for origin and domestication of grape (Vitis vinifera L.), where wild clones still grow in forest areas (This et al. 2006; Ekhvaia and Akhalkatsi 2010). Grapevines are susceptible to a large variety of debilitating diseases caused by fungi, viruses and bacteria.

M. Arzanlou $(\varangle) \cdot$ M. Bakhshi $\cdot$ S. Khodaie

Plant Protection Department, Agriculture Faculty,

University of Tabriz,

P.O. Box: 5166614766, Tabriz, Iran

e-mail: arzanlou@hotmail.com

S. Moshari

Plant Protection Department, Agriculture Faculty,

Zabol University,

Zabol, Iran
In recent years trunk diseases have become a growing threat for grapevine cultivation worldwide, causing significant economic loss on grapevine industry (Úrbez-Torres et al. 2009). Trunk diseases of vines are caused by fungal species which mainly invade through pruning wounds on aerial woody tissues or through the root system of plants. A wide range of symptoms are associated with trunk diseases including dead spurs and cordon, slow decline and dieback of young and old vines. Decline and dieback symptoms are the result of interruption in the vascular system and production of toxins and other secondary metabolites by the fungal agents (van Niekerk et al. 2006; Úrbez-Torres et al. 2009).

Botryosphaeria canker is one of the most important trunk diseases of grapevine causing cankers and other dieback symptoms such as wood streaking, wedge-shaped discoloration in wood, shoot dieback and cane bleaching in all major viticulture regions throughout the world (van Niekerk et al. 2006; Úrbez-Torres et al. 2009).

Since 2008, there have been several reports on the occurrence of decline symptoms on grapevines in vineyards of East and West Azerbaijan provinces in Northern Iran by local farmers as well as plant protection clinics. The disease symptoms appeared as stunted growth, shoot dieback, cane bleaching, bud necrosis and wedge-shaped wood necrosis in cross section through the wood. During 2009-2010 the disease symptoms were more prevalent and severe in vineyards of this region due to the experience of a very hot (above $40{ }^{\circ} \mathrm{C}$ ) and dry summer (Fig. 1). Isolations were made from the margins of necrotic tissues of wood samples. For initial sterilization, 3-4 cm long cuts were made from wood samples and submerged in $10 \%$ solution of sodium hypochlorite for $3 \mathrm{~min}$ and then rinsed with sterile water and dried using sterile paper towels. Small pieces of tissue were cut from the middle part of sterilized wood segments and dipped in $1 \%$ solution sodium hypochlorite for $30 \mathrm{~s}$, to ensure elimination of saprophytic fungi, and subsequently 

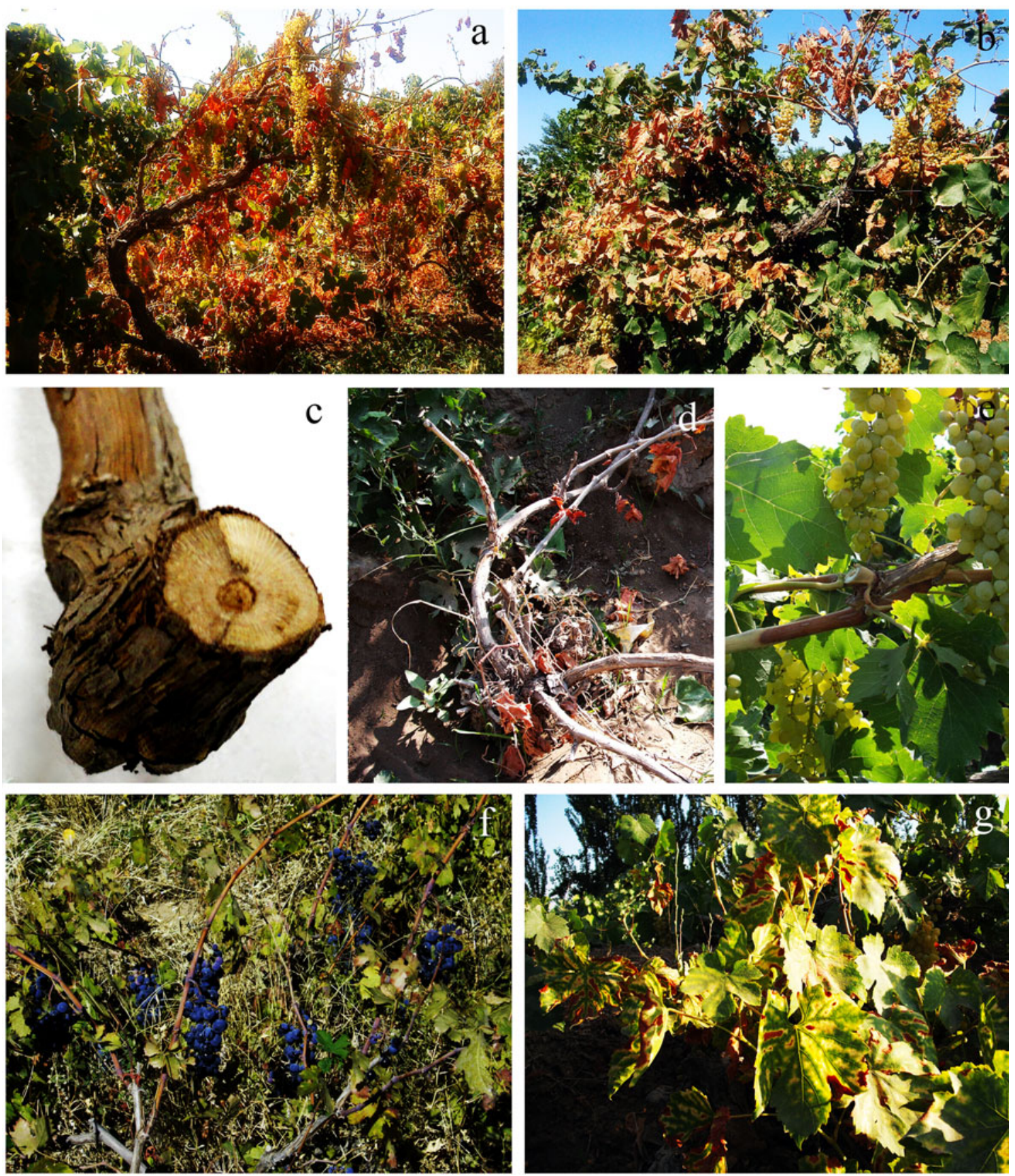

Fig. 1 Disease symptoms on a mature grapevine infected with Botryosphaeria dothidea. $\mathbf{a}, \mathbf{b}$ stunted growth, shoot dieback; $\mathbf{c}$ wedge-shaped wood necrosis; d bud necrosis; e cane bleaching; f shoot dieback; $\mathbf{g}$. leave chlorosis

rinsed with sterile water. Five pieces, approximately $5 \times 1 \times$ $1 \mathrm{~mm}$, were placed on $2 \%$ malt extract agar (MEA, Fluka, Germany) amended with $2 \mathrm{ml}$ of $25 \%$ lactic acid per liter of medium and incubated in the dark at $25{ }^{\circ} \mathrm{C}$. Cultures were examined in two-day intervals and pure cultures were established using a single-spore technique. Pure cultures were preserved on PDA in $2 \mathrm{ml}$ microtube slants at $4{ }^{\circ} \mathrm{C}$ in the Culture Collection of Tabriz University (CCTU; accession no. CCTU 735). On the basis of morphological characteristics the isolates were identified as Botryosphaeria. Colonies were moderately fast growing; reaching a diameter of $31 \mathrm{~mm}$ after 3 days of incubation at $25^{\circ} \mathrm{C}$, with abundant aerial mycelium, initially white, becoming grey or dark grey by age. Conidiomata were induced on pine needle agar medium; semiimmersed to erumpent, dark brown to black, globose to ovoid, up to $850 \mu \mathrm{m}$ diam and $950 \mu \mathrm{m}$ high, uni- or multilocular, eustomatic; wall composed of dark brown, thick-walled texture angularis outer layer, becoming hyaline, thin-walled towards inner layer, oozing after a week time on pine needle agar. Conidiophores hyaline, smooth, thin-walled, cylindrical, 

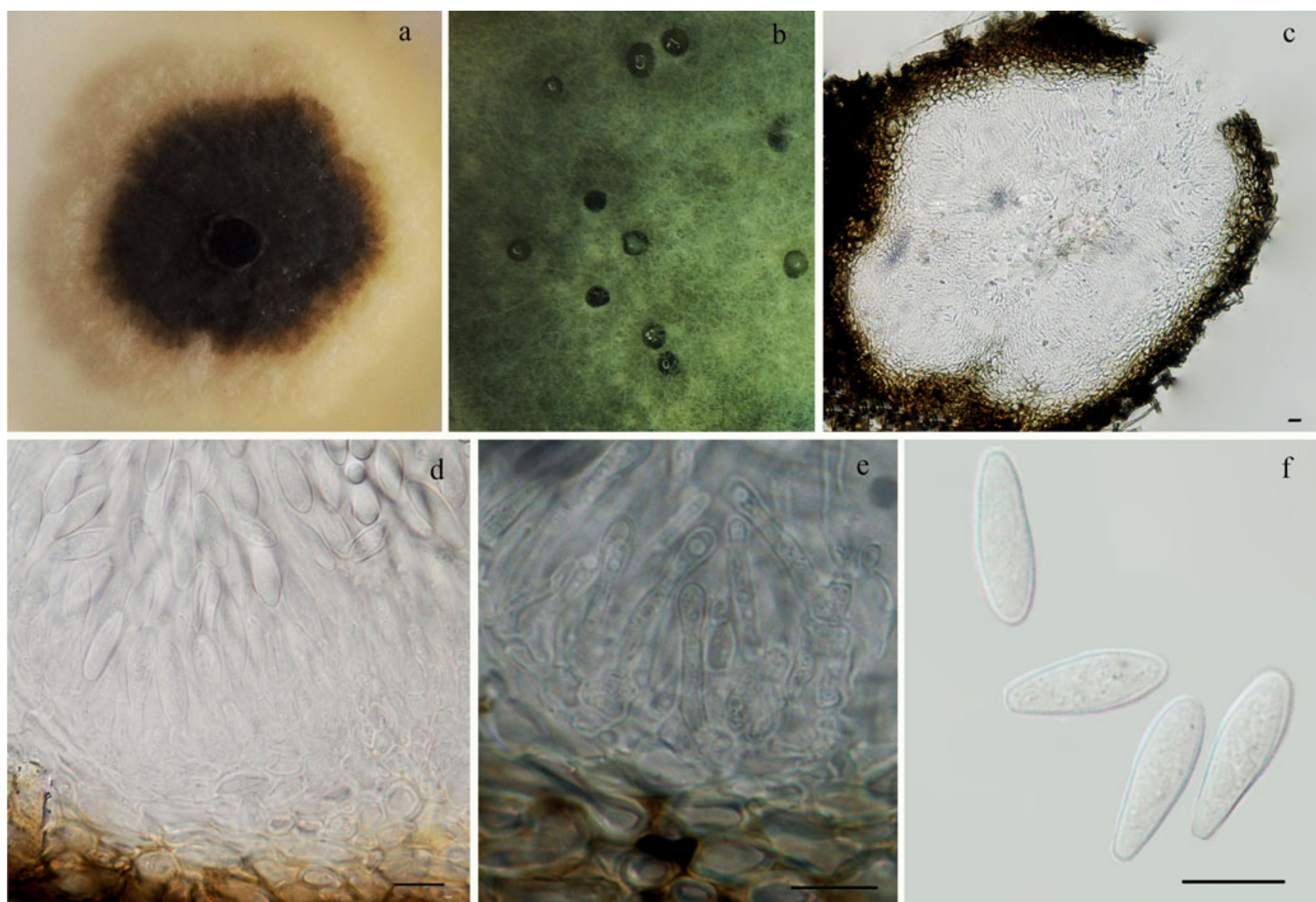

Fig. 2 Botryosphaeria dothidea CCTU 735. a colony morphology on MEA; b conidiomata developed on pine needle agar; $\mathbf{c}$ cross sections through pycnidium; d, e conidiogenous cells; $\mathbf{f}$ conidia. Scale bars $=10 \mathrm{um}$

sometimes branched at the base, $12-20 \times 3-5 \mu \mathrm{m}$, formed from cells lining the inner wall of the pycnidium. Conidiogenous cells, hyaline, smooth, integrated, cylindrical, producing one or more conidia apically, the first conidium holoblastic and subsequent conidia enteroblastic, proliferating percurrently to produce conidia at successively higher levels on annellated conidiogenous cells. Conidia were fusiform to fusiformellipsoid with a truncate base and sub-obtuse apex, aseptate, hyaline, thin-walled, measuring (15-) 18-20 (-22) $\times(4-) 5.5-$ $6.5(-8) \mu \mathrm{m}, 95 \%$ confidence limits $=17.91-19.48 \times 5.29-$

a

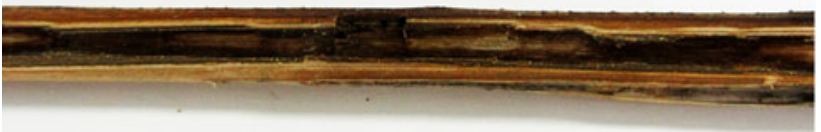

d
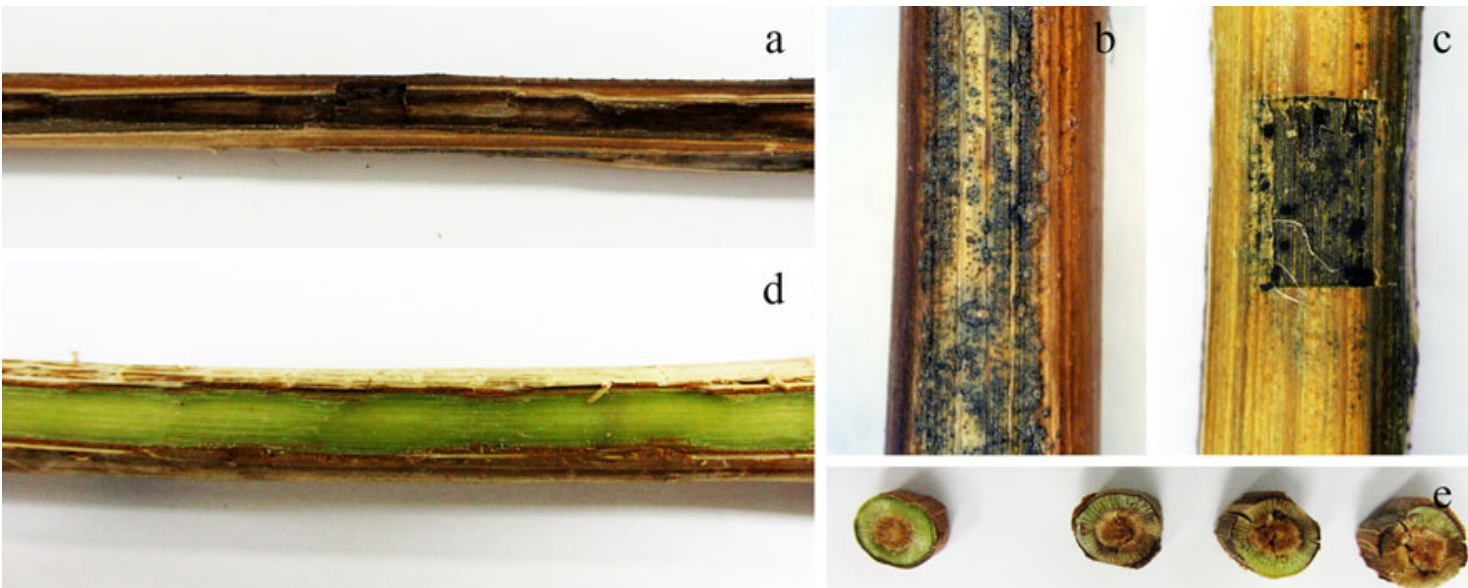

Fig. 3 Pathogenicity assay using excided shoot method. a cortex necrosis and discoloration on inoculated twig; $\mathbf{b}, \mathbf{c}$ conidiomata developed on inoculated twigs after one month; $\mathbf{d}$ control did not develop any disease symptom; e cross section through inoculated shoots (right) and cross section through control shoot (left) 
$6.1 \mu \mathrm{m}$ (mean \pm S.D. of 35 conidia $=18.7 \pm 2.18 \times 5.72 \pm$ $1.16 \mu \mathrm{m}, \mathrm{L} / \mathrm{W}$ ratio $=3.31 \pm 0.9$ ) (Fig. 2). Morphological characteristics of the isolates were in agreement with the description for Fusicoccum aesculi Corda (Qiu et al. 2008). The identity of species was further confirmed by amplification and sequencing of the rDNA internal transcribed spacer region (ITS1-5.8SITS2) using ITS1 and ITS4 (White et al. 1990) universal primers. The reaction mixture and cycling conditions were the same as described by Arzanlou and Khodaei (2012). BLAST search against the nucleotide sequence data at GenBank showed $100 \%$ similarity with Botryosphaeria dothidea isolates from GenBank. The sequence for the isolate CCTU 735 is available in GenBank with the accession number JQ663991. On the basis of molecular confirmation and morphological characteristics the fungus was identified as Botryosphaeria dothidea (Qiu et al. 2008). Excised shoot assay was used to evaluate pathogenicity of the isolates in laboratory condition. Shoots, $10-15 \mathrm{~mm}$ in diameter and $25 \mathrm{~cm}$ in length, were collected from healthy mature vines of $\mathrm{cv}$. Askari, from a vineyard at Agricultural and Natural Resources Research Institute, West Azerbaijan, Urmia. After removal of leaves, shoots were surface-sterilized with $10 \%$ solution of sodium hypochlorite for $10 \mathrm{~min}$, then rinsed with sterile water and dried using sterile paper towels. Three shoots were inoculated with one of the five isolates of Botryosphaeria dothidea. For inoculation, shoots were wounded $12 \mathrm{~cm}$ from the top by removing a cortex flap $(5 \times 8 \mathrm{~mm})$ with a sterile scalpel. A plug of the same size from a 5-days-old colony on MEA was then placed on the exposed shoot surface and covered with Parafilm strip and the control shoot was filled with plug of MEA. Inoculated shoots were placed in a plastic container containing moistened filter papers, in order to keep the relative humidity high and were maintained in a laboratory condition at $25^{\circ} \mathrm{C}$ with natural day light. Shoots were examined after 28 days for disease progress. Longitude sections were made from above and below the inoculation point and wood necrosis was observed in inoculated shoots with the Botryosphaeria dothidea isolates.
The control did not develop any disease symptoms (Fig. 3). To perform Koch's postulates, sections of tissue from each replicate was cultured on MEA and incubated at $25^{\circ} \mathrm{C}$, the same fungus was recovered from inoculated shoots; while, no fungal growth was observed in control.

Even though Botryosphaeria dothidea has a wide host range and represents a well known grapevine pathogen all over the world, to the best of our knowledge this is the first report on occurrence of this species on grapevine in Iran.

Acknowledgments The authors would like to thank the Research Deputy of the University of Tabriz and the Studienstiftung Mykologie, for financial support. The authors are grateful to Prof. Walter Gams for the critical reading of this manuscript and his valuable comments and corrections.

\section{References}

Arzanlou M, Khodaei S (2012) Aureobasidium iranianum, a new species on bamboo from Iran. Mycosphere 3:404-408

Ekhvaia J, Akhalkatsi M (2010) Morphological variation and relationships of Georgian populations of Vitis vinifera L. ssp. sylvestris (C.C. Gmel.). Hegi Flora 205:608-617

FAO (Food and Agriculture Organization of the United Nations) (2009) FAO statistical databases. http://www.fao.org/

Qiu Y, Savocchia S, Steel CC, Ash GJ (2008) Botryosphaeria dothidea associated with grapevine trunk disease in south-eastern Australia. Australas Plant Pathol 37:482-485

This P, Lacombe T, Thomas MR (2006) Historical origins and genetic diversity of wine grapes. Trends Genet 22:511-519

Úrbez-Torres JR, Adams P, Kamas J, Gubler WD (2009) Identification, incidence, and pathogenicity of fungal species associated with grapevine dieback in Texas. Am J Enol Vitic 60:497-507

Van Niekerk JM, Fourie PH, Halleen F, Crous PW (2006) Botryosphaeria spp. as grapevine trunk disease pathogens. Phytopathol Mediterr 45 (Suppl):43-54

White TJ, Bruns T, Lee S, Taylor J (1990) Amplification and direct sequencing of fungal ribosomal RNA genes for phylogenetics. In: Innis MA, Gelfand DH, Sninsky JJ, White TJ (eds) A guide to methods and applications. Academic, San Diego, pp 315-322 